
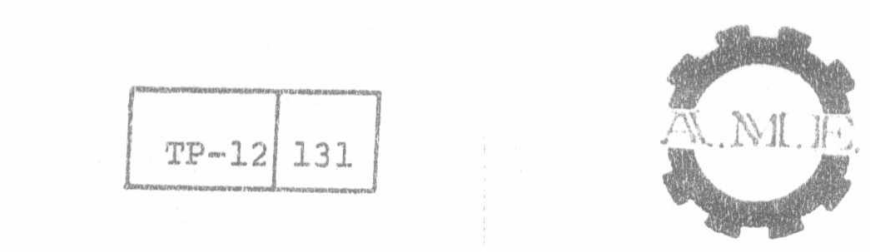

MILITARY TECHNICAL COLLEGE

CAIRO - EGYPT

\title{
STEADY STATE SHAPE CONTROL OF COLD ROLLED \\ STEEL, SHEETS
}

G.A. Hassan*, G.Y. Ibrahim**

ABSTRACT

In the commertial utilization of sheets produced by cold rolling: it is desirable that the gauge of the material be as uniform as possible and the shape defects are minimum. Flatness : of cold rolied products is important when they are used in some fielas such as rocket engine casings and other aerospace: hardware.

: A steady state multivariable control scheme is presented in: the paper aiming at controlling the minimum and maximum thicknesses of the rolled sheets against any disturbance. Required models are derived in general form and the model gain coeffic: ients are obtained for the cold rolling line of the Egyptian

Iron and steel company.

The paper presents the different ways of applying the propos-: : ed control scheme including simple manual method suitable for the developed countries.

\section{INTRODUCTION}

cold rolling is one of the important processes used in the production of : sheets from different materials and for various purposes. In order to

: increase the productivity of the rolling process, it has to be controlled. This increases the output per unit consumption of energy and reduces the. tolerance in the sheet thickness to accepted levels.

: The rolling process is a multivariables one with a good number of variables interacting together to perform the rolling operation [1]. As a matter of fact, the rolled sheet has a crowned cross-section due to the : : deformation of the roll during operation producing thickness variation in the lateral direction $[1,2]$. Besides, uncontrolled disturbances in the

* Assistant Professor, ** Graduate Student, Dept. of Mechanical Design and Production, Faculty of Engineering, Cairo University, Giza, Egypt. 
electrical and hydraulic systems of the rolling mill result in an axial : variation of the sheet thickness.

The control of the sheet gauge requires accurate measurement and control : instrumentations. Some of the used techniques are available in the literature [3-11]. However, there is no quantitative analysis handing the automatic gauge problem as a multivariable one and providing control : models relating the input and output variables.

The work presented in this paper outlines a steady state model relating : two variables controlling the sheet shape and two input variables of the rolling process. The variation in the sheet shape due to uncontrollea disturbances is automatically or manually compensated according to a : proposed control scheme. The control models are quantitatively presented for Helwan-Iron and Steel Company cold rolling mill. 2. SYSTEM VARIABLES

With the rolled sheet centred at midspan of the work rolls of the rollire : stand, the maximum and minimum thicknesses of the sheet lie at its mid span and ends respectively as illustrated in Fig.l. The profile of the rolled sheet is controlled by the shape of the work rolls profile depend: ing on the rolling conditions.

Let the minimum thickness of the rolled sheet is $t_{\text {min }}$ and its maximum thickness is $t_{\max }$ (see Fig.l). The sheet shape may be controlled through controlling both $t_{\min }$ and $t_{\max }$ (controlled variables).

With two controlled variables, at least two control variables are requirea. It is possible to use any of the following two sets of the cola : ' rolling process variables: (screw down position S and rolling force F) aru (entry and exit tensile forces in the sheet). The former set is usea ir the present work.

\section{STEADY STATE CONTROL MODEL}

: The controlled variables: $t_{\min }$ and $t_{\max }$ are functions of the control variables: $\mathrm{S}$ and $\mathrm{F}$ and the roll dimensions $[1,12]$. That is:

$$
\begin{aligned}
\vdots & t_{\min }=\mathrm{S} \\
& +\frac{8 \mathrm{~F}(\mathrm{~L}-\mathrm{b}-2 \mathrm{n})}{3 \pi \mathrm{D}^{4} \mathrm{E}}\left[\frac{(\mathrm{L}-\mathrm{b}-2 \mathrm{n})^{3}}{8 \mathrm{~W}}+\mathrm{L}^{2}+2 \mathrm{~W}-0.5(\mathrm{~L}-\mathrm{b})(\mathrm{L}-\mathrm{b}-2 \mathrm{n}) \mid\right. \\
& +\frac{10 \mathrm{~F}}{\pi \mathrm{ED} \mathrm{D}^{2}}\left[\frac{\left(\mathrm{L}^{2}-\mathrm{b}^{2}\right)}{2 \mathrm{~W}}-\mathrm{n}(\mathrm{L}-\mathrm{n}) \mid\right.
\end{aligned}
$$

$\vdots$

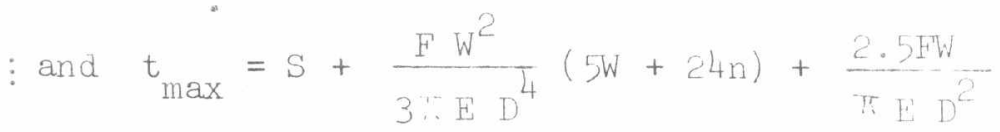

: where $L, W, n$ and $D$ are roll dimensions(see Fig.2), b is the width of the : rolled sheet and $\mathrm{E}$ is the elastic modulus of the roll material.

¿. 
For purpose of steady state control of the exit sheet thicknesses $t_{\text {min }}$ : and $t_{\max }$, the changes in these parameters $\left(\Delta t_{\min }\right.$ and $\left.\Delta t_{\max }\right)$ may be related to the changes in the control variables ( $\Delta S$ and $\Delta F$ ) through the : following relationships $[1,13]$ :

$$
\begin{aligned}
& \Delta t_{\min }=K_{11} \Delta S+K_{12} \Delta F \\
& \text { : and } \quad \Delta t_{\max }=K_{2 l} \Delta S+K_{22} \Delta F \\
& \text { : where } \quad \mathrm{K}_{11}=\frac{\partial t}{\partial \mathrm{s}} \min =1 \\
& \vdots \quad \mathrm{K}_{12}=\frac{\partial t_{\min }}{\partial \mathrm{F}} \\
& \text { : } \\
& =\frac{8(L-b-2 n)}{3 \pi D^{4} E}\left[\frac{(L-b-2 n)^{3}}{8 W}+L^{2}+2 n W-0.5(L-b)\right. \\
& (L-b-2 n)]+\frac{10}{\pi E D^{2}}\left[\frac{\left(L^{2}-b^{2}\right)}{2 W}-n(L-n)\right] \\
& K_{21}=\frac{\partial t_{\max }}{\partial S}=1 \\
& \vdots \quad K_{22}=\frac{\partial t_{\max }}{\partial F} \\
& =\frac{W^{2}}{3 \pi E D^{4}}(5 w+24 n)+\frac{2.5 W}{\pi E D^{2}}
\end{aligned}
$$

The gain coefficients $K_{12}$ and $K_{22}$ of Eqs.(3) and (4) are functions of the: roll dimensions as illustrated in Eq.(5). $K_{I l}$ and $K_{2 l}$ equal $I$ as derived
from Eqs.(1) and (2).

$\vdots$ The shape of the rolled sheet is assigned in this control scheme through the measurement of the minimum and maximum thicknesses. The deviation from a preassigned values produces the changes $\Delta t_{\min }$ and $\Delta t_{\max }$. The

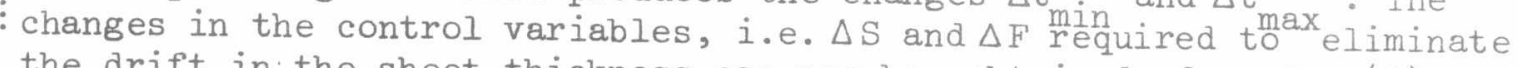
the drift in the sheet thickness can now be obtained from Eqs.(3) and
(4). That is: :

$$
\begin{aligned}
& \Delta S=\frac{1}{K_{11} K_{22}-K_{12} K_{2 I}^{-}}\left\{K_{22} t_{\min }-K_{12} t_{\max }\right\} \\
& \text { and } \Delta F=\frac{1}{K_{11} K_{22}-K_{12} K_{21}}\left\{-K_{21} t_{\min }+K_{11} t_{\max }\right\}
\end{aligned}
$$


Eqs.(6) and (7) represent the steady state model of the proposed control $\vdots$ system which is a multi-input, multi output ore.

\section{PROPOSED CONTROL SYSTEM FOR THE SHEET SHAPE}

: A steady state control system aiming at reducing the deviation of the measured minimum and maximum thicknesses of the cold rolled sheet from certain desired values is illustrated in Fig.3. The system works as

follows:

(i) The minimum and maximum thicknesses of the strip have to be measurea : using suitable transducers such as X-ray thickness gauge.

(ii) The signals from the transducers have to be conditioned using coraitioning amplifiers for the purpose of filterine, amplification and safety against overloading.

(iii) The output signals of the conditioning amplifiers have to be fed : : to a master controller. The desirea values of $t_{\min }$ and $t_{\max }$ have to be

fed also to the controller(as defined from a computer aidea optimization program of the rolling process $[12,14]$ ). The controller manipulates the : error in $t_{\min }$ and $t_{\max }$, i.e. $\Lambda_{\text {Iin }}$ ari $\Delta t_{\max }$ and then uses the steady state control model of Eqs.(6) and (7) to calculate the required correc- : tions in the process control variables.

(iv) The output of the master controller will be the two correcting signals $\triangle S$ and $\Delta F$ which have to be feà to the indiviaual controllers of : the screw down (gap) position and the rolling force respectively.

( $(v)$ The output signals from the screw down and the rolling force controllers arive the cold rolling mill so that the drifts in $t_{\min }$ ara $t_{\max }$ are : reduced.

The proposed control system described in the previous steps may be practically applied in three different forms as follows:

(a) Using on-line digital microcomputers:

The microcomputer replaces the master controller of Fig. 3 and may replace the rolling force ana screw down position controllers. The system in this case is called direct digital control system $[15,16]$. The control model is programmed in a suitable language and reasonable interfaces betweer : the computer and the process have to be used. In such case it is easier to monitor all the process variables ard provide automatic alarming (warning signals) in case something has gcne wrong. This system worked : successfully in other processes $[17,16]$. It is more sophisticated than the data monitoring systems $[19,20]$.

:(b) Using programmable controllers:

The programmable controller is an analogue one based on an electronic microprocessor which has to be built(designed) to satisfy the control : model. Potentiometers set the desired values of the sheet thickness anu

the optimal operating conditions of the mill. Programmable controllers were introduced to the cold rolling mills in the 1960's [21].

(c) Using manual controllers:

Here, the human operator replaces the master controller. He reads the : minimum and maximum thicknesses using suitable gauges and compares them with the desired values. Depending on the errors he can set the cortroll: ers of the rolling force and screw down position according to the computea i.. 
corrections using the control model. This method may be reasonable for the

: developed countries where there is a lack of knowledge and facilities regarding the first two types.

5. CASE STUDY

The cold rolling $4 \mathrm{high}$ reversing mill of the Egyptian Iron and Steel : Company is considered here as a case study where the control strategy presented in the paper will be applied. The line has the following dimensions $[22]$ :

$\vdots$

Roll barrel length, $W=1.0 \mathrm{~m}$ Distance between the centres of the roll neck bearings, $L=1.2 \mathrm{~m}$

: Diameter of the back up roll, $D=1.3 \mathrm{~m}$

: The rolls of the mill are cast steel having an elastic modulus of $18 x$ $10^{10} \mathrm{~N} / \mathrm{m}^{2}[14]$

: For a one meter sheet width $(\mathrm{b}=1 \mathrm{~m})$, the gain coefficients of the control model are calculated using Eq.(5) and given by:

$$
\therefore \quad \begin{aligned}
K_{11} & =1 \\
K_{12} & =2.63, \mathrm{um} / \mathrm{MN} \\
K_{21} & =1 \\
\vdots \quad K_{22} & =8.87 \mathrm{um} / \mathrm{MN}
\end{aligned}
$$

Combining Eqs.(6),(7) and (8) gives the steady state control model of the : case study rolling mill. That is:

$$
\begin{array}{ll}
\Delta & \Delta S=1.42 \Delta t_{\min }-0.42 \Delta t_{\max } \\
\text { and } & \Delta F=0.16 \times 10^{6}\left(\Delta t_{\max }-\Delta t_{\min }\right) \quad M N
\end{array}
$$

where $\Delta t_{\min }$ and $\Delta t_{\max }$ are in meters.

:To facilitate using Eqs(9) and (10) by the processing operator in a prompt way, a nomogram is designed to relate the controlled variables change $\Delta t_{\min }$ and $\Delta t_{\max }($ in $\mathrm{mm}$ ) and the controlling variables change : $\Delta S($ in $\mathrm{mm})$ and $\triangle \mathrm{F}($ in $\mathrm{MN})$. The nomogram is illustrated in Fig. 4 for thickness variation up to $\pm 0.05 \mathrm{~mm}$. $\vdots$

\section{DISCUSSIONS}

: A steady state control system based on linear models was presented ir the paper for the purpose of on-line continuous control of the sheet thickness variation during the cold rolling process. The linear forms of the models : are preferred for computer control applications especially with the micro 
\begin{tabular}{|l|l|}
\hline $\mathrm{TP}-12$ & 136 \\
\hline
\end{tabular}

FIRS'I' A.M.E. CONE'LRENCE

29-31 l'ay 1984; Cairo

types where the speed is limited compared with the main frant ores. On

: the other hand, the linear model allows the construction of simple

nomograms of linear characteristics where it is easy for the operator

:

to follow up.

The potential of the control system presented here depends on the possibility of providing an existing cold rolling line with electronic

: instrumentations for measurement and control of the process variables. As an alternative, the paper clarifies the way of manual adjustment of the control variables against long term disturbances in the sheet

: thickness.

The stability of the system may be improved by allowing a tolerance band : for $t_{\min }$ and $t_{\max }$ outside which the control system operates. Moreover, feedback and/or feedforward control strategies may be used [18].

\section{REFERENCES}

: $\quad$ I. Roberts,W.L., "Cold Rolling of Steel", Marcel Dekker Inc.( I978)

z. Larke,E.C., "The Rolling of Strip, Sheet and Plate", Chapmar and Hall Lta. ( 1963) : 3. Sims,R.B., "Gauge Meter for Strip Mills", Engineerine, 17), p. s3,

4. Baarck,W.R., "The Generation and Behaviour of X-Rays in Thickress:

: $\quad$ Measurements", Iron and Steel Engineer Year Book, p.860, (1963)

5. Mizukoshi,T,, Umeda,S. and Shimisu, Ni., "Gamma Ray Thickness Gauge for Strip Processing Lines", ibia, p.33,( 1968)

: 6. Hessenberg,W. and Sims,R.B., "Principles of Continuous Gauge control in Sheet and Strip Rolling", Proc. Inst. Mech. Eng., 166,

7. Sims,R.B. and Briggs,P.R., "Control of Strip Thickness in Hot aria: Cold Rolling by Automatic Screwdown", Sheet Metal Industries, 31 ,

6. Petraske,K.A. and Sills,R.M., "Developments in Drive Systems and Gauge Control for Reversing Cold Mills", Iron and Steel Engineer Year Book, p.991,(1961)

9. Wallace,J., "Fundamentals of Strip Mill Automatic Gauge Control Systems", ibid, p.753,( (1964)

10. Steinbrecher, 0., "Automatic Gauge Control for Cold Rolling Nills" , ibid, p.174, (1969)

11. Stone,M., "Hyaraulic Automatic Gauge Control Mills", ibia, p.313, (1973)

12. Ibrahim,G.Y., M.Sc. Thesis, Faculty of Engineering, Cairo 13. Raven,F.H., "Automatic Control Engineering", McGraw Hill Book
Co.,(196.8)

14. Rao,S. and Kumar,A., "Optimization of Cold Rolling by Nonlinear Programming", Trans. of the ASME, J. of Engineering for Industry,

15. Giusti,A., Otto,R. and Williams, T., "Direct Digital Computer. Control", Control Engineering, 9, p.104, June(1962)

16. Bowden,K.R., "ANew Approach to Digital Process Control", Nieasurement and Control, 9, p.315, Sept.(1976) 
17. Parnaby,J., Battye,P., Hassan,G.A. and Hadwell,C., "Computer Controlled Injection Moulding and Extrusion", Plasties and Rubber Processing, p.89, Sept.(1978)

18. Hassan,G.A. and Parnaby,J., "Model Reference Optimal Steady State Adaptive Computer Control of Plastics Extrusion Processes" , Polymer Eng. Science, 21, p.276, April(1981)

19. Roth,J., "On Line Computer Systems in the Metals Industry - A Survey", Iron and Steel, 25, p.251,(1966)

20. Bryan,T. and Horn, J., "Applications of Computers to Temper Mill: Control", Iron and Steel Engineer Year Book, p.405, ( 1968 )

: 21. Steinbrecher, 0., "Programmed Cold Rolling Reversine Mills", ivia, p. 303, ( 1969)

22. Private Communications with the Iron and Steel Company, Helwan, Egypt

\section{NOMENCLATURE}

Width of rolled sheet, $m$

Back up roll diameter, m

Elastic modulus of roll material, $\mathbb{N} / \mathrm{m}^{2}$

Rolling force, $N$

Gain coefficient

Distance between centres of roll neck bearings, $m$

Distance between the centre of the roll neck bearing and the

edge of the roll barrel, $m$

Screw down position, $m$

$\mathrm{S}$

${ }^{t} \min$

Exit thickness of the sheet at its edge, $m$

Exit thickness of the sheet at its centre, $m$

Length of roll barrel, $m$

$\vdots \Delta$

Change in control and controlled variables 


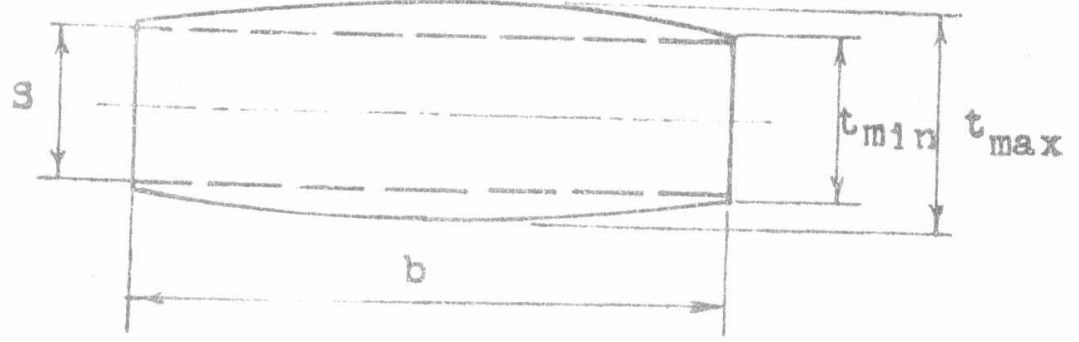

F1g.1 Sheot thicknes protlla.

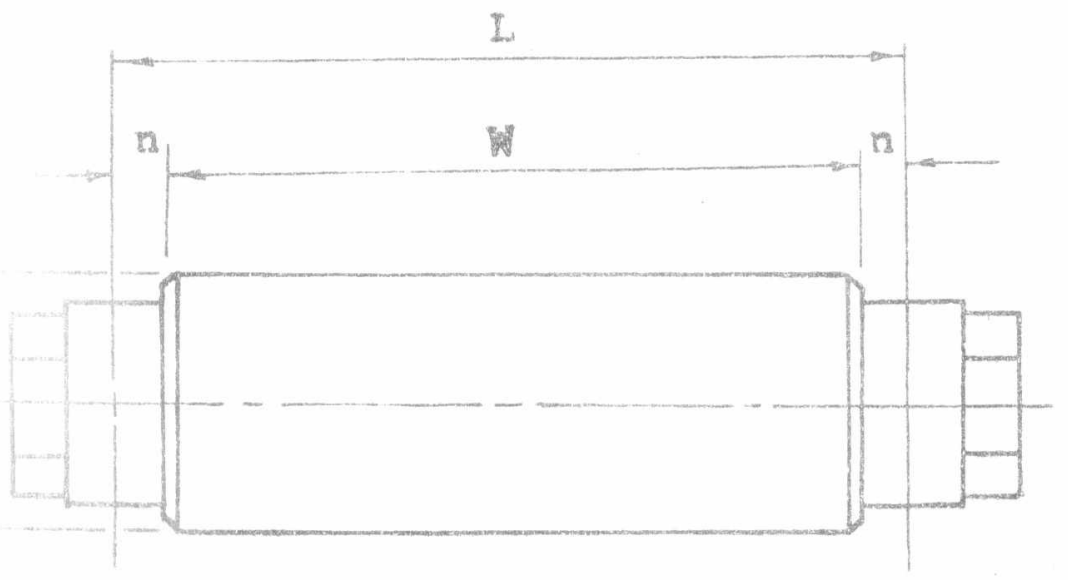

Fy 18.2 Back up roll dimenalone.

i. 


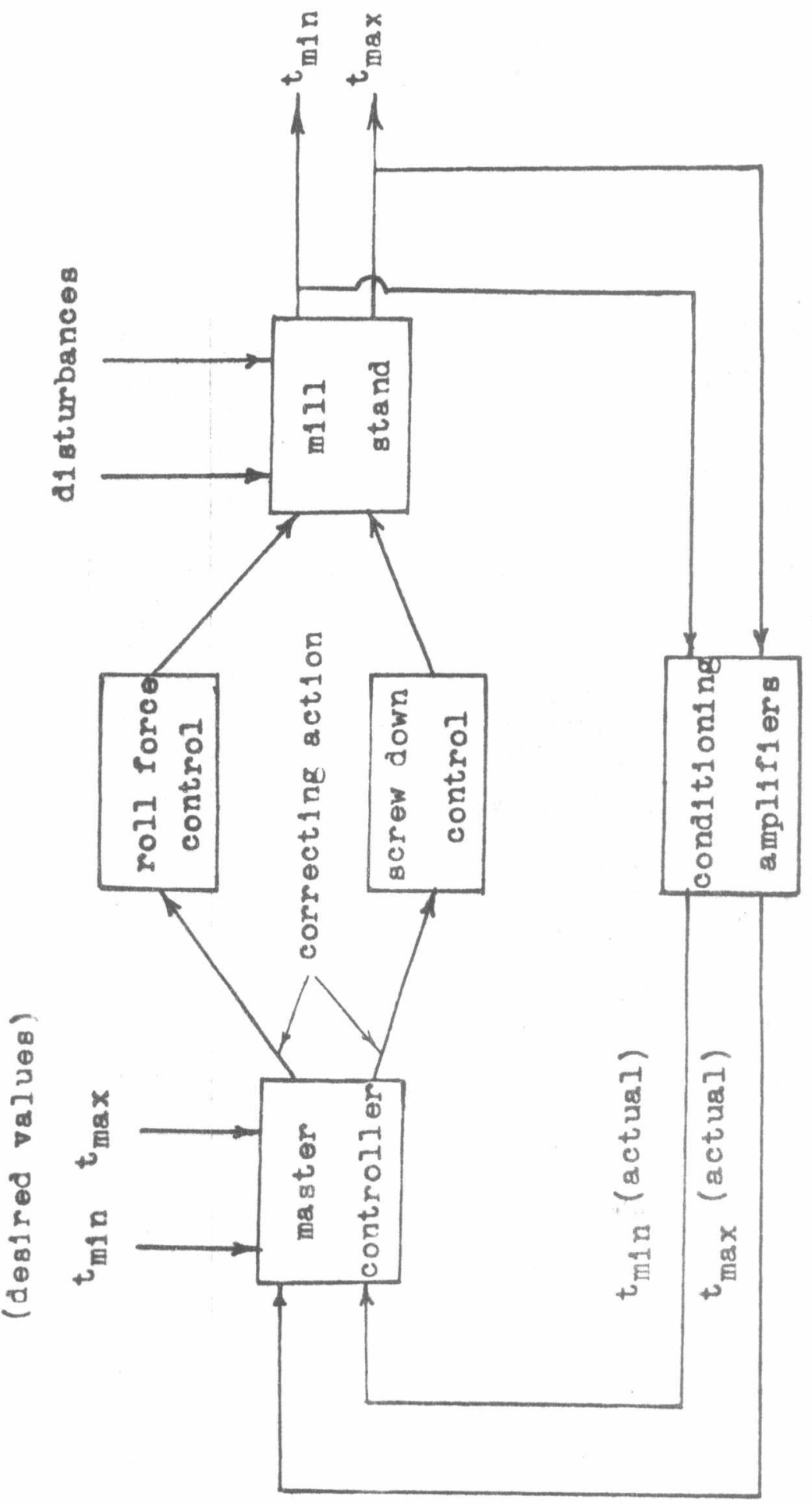




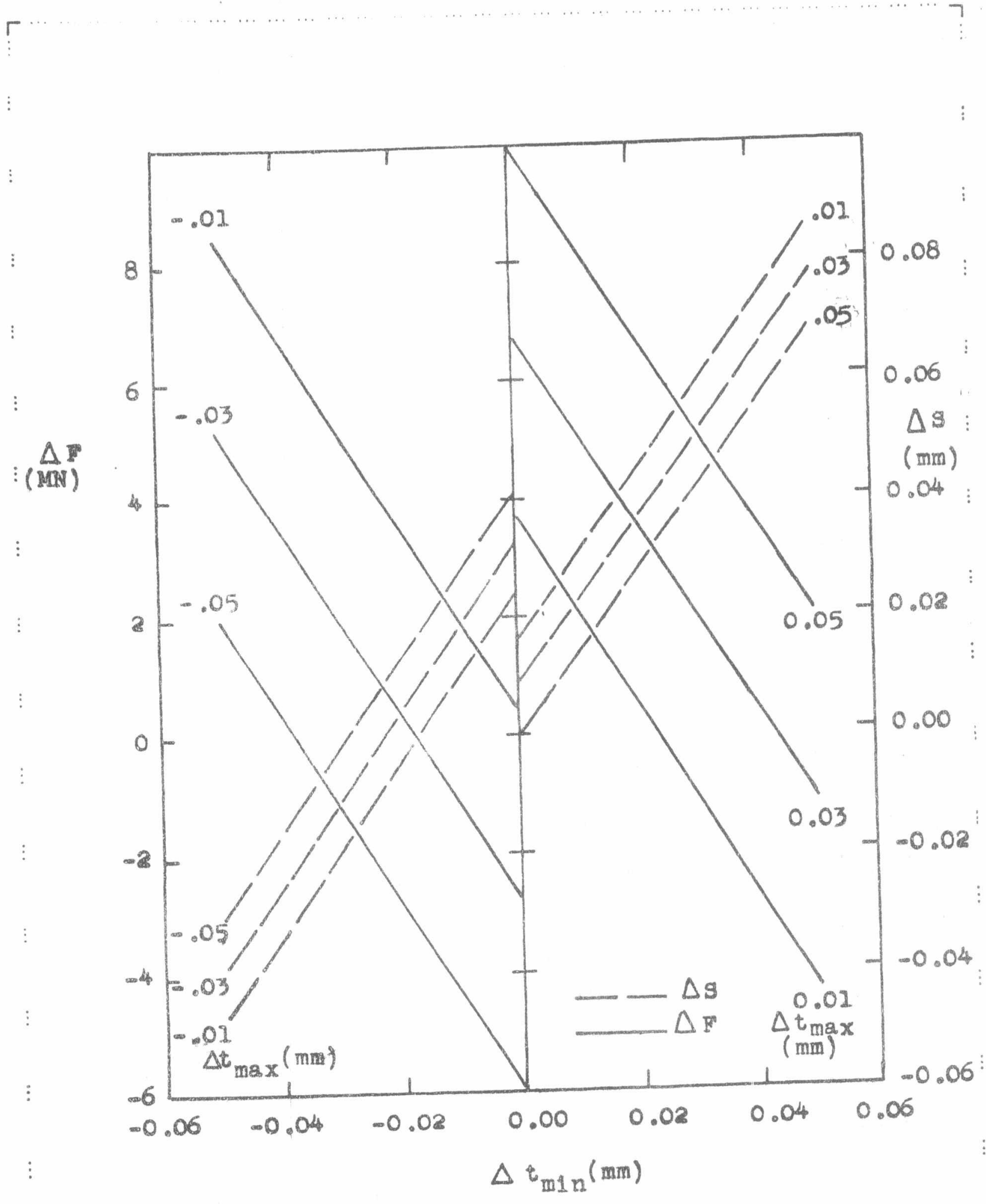

1g. Nomogram for menuel control of shoet thickness. 